\title{
HUBUNGAN KELAINAN LETAK JANIN , PREEKLAMSIA, KETUBAN PECAH DINI DENGAN PERSALINAN SECTIO CAESAREA
}

\author{
Puji Setiana, Herawati, Sutriyati \\ Program Studi Diploma IV Kebidanan Universitas Kader Bangsa Palembang \\ Jl. Mayjend H.M. Ryacudu No. 88 Palembang Telp. (0711) 517744 - 510173 \\ Email : pujisetiana8@gmail.com
}

\begin{abstract}
Abstrak
Sectio Caesarea adalah suatu persalinan buatan dimana janin dilahirkan melalui suatu insisi pada dinding depan perut dan dinding rahim dengan syarat rahim dalam keadaan utuh serta berat janin di atas 500 gram. Penelitian ini bertujuan untuk mengetahui hubungan kelainan letak janin, preeklamsia, dan ketuban pecah dini dengan persalinan sectio caesarea di Rumah Sakit TK IV Dr. Noesmir Baturaja tahun 2018. Metode yang digunakan dalam penelitian ini adalah survei analitik dengan pendekatan cross sectional. Pada Penelitian ini jumlah populasi 683 responden dan jumlah sampel diambil sebagian dari jumlah populasi yang berjumlah 87 responden. Jenis data dalam penelitian ini adalah data sekunder. Uji statistik yang digunakan uji chi- square. Dari hasil uji statistik didapatkan adanya hubungan kelainan letak janin dengan persalinan sectio caesarea, dengan analisis bivariat hasil uji chi-square diperoleh $P$ value $(0,001)<\alpha(0,05)$, adanya hubungan preeklamsia dengan persalinan sectio caesarea, dengan analisis bivariat hasil uji chi-square diperoleh $P$ value $(0,031)<\alpha(0,05)$, dan ada hubungan ketuban pecah dini dengan persalinan sectio caesarea, dengan analisis bivariat hasil uji chi-square diperoleh $P$ value $(0,000)<\alpha(0,05)$. Hasil penelitian ini diharapkan dapat menambah referensi,wawasan dan pengetahuan yang berkaitan dengan persalinan sectio caesarea.
\end{abstract}

Kata kunci : Sectio caesarea, kelainan letak janin, preeklamsia, ketuban pecah dini

\section{Abstract}

Sectio Caesarea is an artificial labor where the fetus is born through an incision in the front wall of the abdomen and uterine wall with the condition that the uterus is intact and the fetus weighs above 500 grams. This study aims to determine the relationship of abnormalities of fetal location, preeclampsia, and premature rupture of the membranes with caesarean section delivery at TK IV Hospital Dr. Noesmir Baturaja in 2018. The method used in this study is an analytical survey with a cross sectional approach. In this study the total population was 683 respondents and the number of samples was taken in part from the total population of 87 respondents. The type of data in this study is secondary data. Statistical test used chi-square test. From the results of statistical tests it was found that there was a relationship between abnormal location of the fetus and caesarean section delivery, with bivariate analysis the results of the chi-square test obtained $P$ value $(0.001)<\alpha(0.05)$, there was a relationship between preeclampsia and cesarean delivery, with bivariate analysis Chi-square obtained $P$ value $(0.031)<\alpha(0.05)$, and there was a relationship between premature rupture of membranes and caesarean section delivery, with bivariate analysis of the chi-square test results obtained $P$ value $(0,000)<\alpha(0.05)$. The results of this study are expected to be able to add references, insights and knowledge related to Caesarean section delivery.

Keywords: Sectio caesarea, fetal location abnormalities, preeclampsia, premature rupture of membranes 


\section{PENDAHULUAN}

Data World Health Organization (WHO) rata-rata tindakan sectio caesarea berkisar 5\% sampai $15 \%$ per 1000 kelahiran dunia. Pada Tahun 2014 di Amerika Serikat rata-rata sectio caesarea meningkat hingga $29,1 \%$ per 1000 kelahiran, di Inggris telah mencapai 21,4 $\%$, per 1000 kelahiran .Pada tahun 2001 dan 2003 angka kejadian sectio caesarea di Kanada adalah 22,5\% per 1000 kelahiran hidup. Data tersebut menunjukkan bahwa secara global, khususnya di negara-negara maju, bahwa angka tindakan persalinan melalui sectio caesarea terbilang tinggi. Pada tahun 70an permintaan sectio caesarea adalah $5 \%$ kini lebih dari $50 \%$ ibu hamil menginginkan persalinan sectio caesarea (Winkjosatro,2015).

Berdasarkan Survei Demografi dan Kesehatan Indonesia (SDKI) tahun 2012, angka kejadian sectio caesarea berjumlah 921.000 dari 4.309 .000 persalinan atau $22,8 \%$ dari seluruh persalinan.Data riset kesehatan menunjukkan sectio caesarea 9,8\% dengan proporsi tertinggi di DKI Jakarta $19,9 \%$ dan terendah di Sulawesi Tenggara 3,3\% (RISKESDAS,2013).

Indonesia mengalami peningkatan sectio caesarea pada tahun 2005 sebesar 51,59\% per 100.000 kelahiran hidup dan tahun 2006 sebesar 53,68\% per 100.000 kelahirandan dalam 20 tahun terakhir ini terjadi kenaikan proporsi sectio caesarea dari $5 \%$ menjadi $20 \%$. Jumlah persalinan sectio caesarea di rumah sakit pemerintah adalah sekitar $20-25 \%$ dari total persalinan, sedangkan di rumah sakit swasta jumlahnya sangat tinggi, yaitu sekitar $30-80 \%$ dari total persalinan (Profil Dinkes RI,2010).

Faktor yang mempengaruhi tindakan sectio caesarea yaitu partus lama,riwayat sectio caesarea, preeklamsia ringan, preeklamsia berat, placenta previa, CPD , gemeli, gawat janin, serotinus , kelainan letak janin, ketuban pecah dini (Mochtar, 2012).

Penelitian tentang persalinan tindakan mengalami peningkatan menjadi 168 dari 763 persalinan (22,02\%), angka ini lebih tinggi bila dibandingkan dengan RS Abdoel Moelok pada tahun 2008 jumlah persalinan dengan tindakan sebanyak 361 dan tahun 2009 jumlah persalinan dengan tindakan sebanyak 562 dari 2.753 persalinan di RSUD A.Yani Metro tahun 2011 (20,41\%) (Rekam medik RSU Abdoel Moeloek ,2012).

Penelitian dari 2492 ibu bersalin terdapat $930(37,31 \%)$ dilakukan Sectio Caesarea, sedangkan pada tahun 2013 terjadi peningkatan sebanyak $920(40,76 \%)$ dari 2257 persalinan namun tahun 2014 terjadi penurunan yaitu $390(35,42 \%)$ dari 1101 persalinan tetapi angka ini lebih tinggi dari Rumah Sakit Pemerintah yang angka kejadiannya 20-25\% dan melewati batas maksimal WHO yaitu 5-15\% (Apriani, 2015).

Berdasarkan data yang diperoleh dari rekam medis di Rumah sakit TK IV Dr. Noesmir Baturaja tahun 2016 terdapat 612 persalinan dengan 262 persalinan normal dan 350 persalinan dengan Sectio Caesarea, pada tahun 2017 terdapat 631 persalinan dengan 305 persalinan normal dan persalinanSectio Caesarea 326, sedangkan data pada tahun 2018 sebanyak 683 persalinan dengan 381 persalinan normal dan persalinan dengan sectio caesarea sebanyak 302 tindakan (Rekam Medis Rumah sakit TK IV Dr. Noesmir Baturaja, 2019).

Berdasarkan latar belakang diatas peneliti tertarik untuk meneliti "Hubungan Kelainan Letak Janin, Preeklamsia dan Ketuban Pecah Dini dengan Persalinan Sectio Caesarea di Rumah sakit TK IV Dr. Noesmir Baturaja tahun 2018”. 


\section{METODE PENELITIAN}

\section{Jenis Penelitian}

Penelitian ini menggunakan metode survei analitik melalui pendekatan cross sectional.

\section{Waktu dan Tempat Penelitian}

Penelitian dilakukan pada bulan Mei 2019 di RS.TK.IV Dr. Noesmir Baturaja.

\section{Target/ Subjek Penelitian}

Populasi dalam penelitian ini adalah seluruh ibu bersalin yang pernah di rawat di Rumah sakit TK. IV Dr. Noesmir Baturaja tahun 2018 berjumlah 683 responden. Sampel pada penelitian ini adalah sebagian ibu bersalin yang tercatat direkam medik yang pernah di rawat di Rumah sakit TK. IV Dr. Noesmir Baturaja tahun 2018 yang berjumlah 87 responden.

\section{Data,Intrumen, dan Teknik Pengumpulan Data}

Penelitian dilakukan dengan menggunakan data sekunder. Data yang diperoleh dengan cara mencatatat data dari rekam medik di Rumah sakit TK IV Dr. Noesmir Baturaja tahun 2018.

Teknik pengambilan sampling pada penelitian ini dilakukan secara sistematic random sampling. Teknik pengambilan sampel dilakukan dengan langkah-langkah sebagai berikut :

1. Membuat listing atau daftar populasi ibu bersalin yang terdapat di rekam medik yang berjumlah 683 orang.

2. Menentukan interval sampel dengan menggunakan rumus :

$$
\mathrm{I}=\frac{\mathrm{N}}{\mathrm{n}}=\frac{683}{87}=7
$$

3. Menetapkan sampel pertama dengan cara memilih secara acak dengan mengundi angka 1 sampai 10 .

4. Sampel selanjutnya ditentukan dengan menambahkan nomor sampel pertama dengan interval sampel. Langkah ini dilakukan dengan harapan semua populasi mempunyai peluang yang sama untuk dipilih menjadi sampel.

Data yang terkumpul kemudian di olah melalui tahap-tahap berikut
1. Editing (Pengeditan Data)
2. Coding (Pengkodean Data)
3. Entry Data (Pengolahan Data)
4. Cleaning (Pembersihan Data)

\section{Teknik Analisis Data}

Data yang disajikan dengan mendistribusikan melalui analisis univariat dan bivariat.

\section{Analisis Univariat}

Analisis ini digunakan untuk memperoleh gambaran distribusi frekuensi dan persentase dari semua variabel penelitian, yaitu kelainan letak janin, preeklamsia, ketuban pecah dini (variabel independen) serta sectio caesarea (variabel dependen).

\section{Analisis Bivariat}

Untuk melihat adanya hubungan antara kelainan letak janin, preeklamsia, ketuban pecah dini dengan kejadian sectio caesarea dan disajikan dalam bentuk tabel dengan uji chi-square dengan batas kemaknaan value $\alpha \quad 0,05$ dengan menggunakan sistem komputerisasi (SPSS):
a. Bila $p$ value $\leq$ nilai $\alpha(0,05)$ berarti ada hubungan antara variabel independen dengan variabel dependen
b.Bila $p$ value $>$ nilai $\alpha(0,05)$, berarti tidak ada hubungan antara variabel independen dengan variabel dependen.

\section{HASIL PENELITIAN DAN PEMBAHASAN}

Tabel 1. Distribusi Frekuensi Responden Berdasarkan Persalinan Sectio Caesarea

\begin{tabular}{cccc}
\hline N & $\begin{array}{c}\text { Persalinan } \\
\text { Sectio } \\
\text { Caesarea }\end{array}$ & $\begin{array}{c}\text { Frekuensi } \\
(\mathbf{N})\end{array}$ & $\begin{array}{c}\text { Persentase } \\
(\%)\end{array}$ \\
\hline 1. & Ya & 46 & 52,9 \\
\hline
\end{tabular}




\begin{tabular}{cccc}
\hline $\begin{array}{c}\text { N } \\
\text { o. }\end{array}$ & $\begin{array}{c}\text { Ketuban } \\
\text { Pecah } \\
\text { Dini }\end{array}$ & $\begin{array}{c}\text { Frekuens } \\
\text { i(N) }\end{array}$ & $\begin{array}{c}\text { Persentas } \\
\text { e( } \%)\end{array}$ \\
\hline 1 & Ya & 32 & 36,8 \\
\hline 2 & Tidak & 55 & 63,2 \\
\hline & Jumlah & 87 & 100 \\
\hline 2. & Tidak & 41 & 47,1 \\
\hline & Jumlah & $\mathbf{8 7}$ & $\mathbf{1 0 0}$ \\
\hline
\end{tabular}

Berdasarkan tabel di atas, dapat diketahui bahwa dari 87 responden, ibu yang mengalami persalinan Sectio Caesarea berjumlah $46 \quad(52,9 \%)$ responden, sedangkan ibu yang tidak mengalami persalinan Sectio Caesarea berjumlah $41(47,1 \%)$ responden.

Tabel 2. Distribusi Frekuensi Responden Berdasarkan Kelainan Letak Janin

\begin{tabular}{lccc}
\hline $\begin{array}{c}\text { N } \\
\text { o. }\end{array}$ & $\begin{array}{c}\text { Kelainan } \\
\text { Letak } \\
\text { Janin }\end{array}$ & $\begin{array}{c}\text { Frekuensi } \\
(\mathbf{N})\end{array}$ & $\begin{array}{c}\text { Persentase } \\
(\mathbf{\%})\end{array}$ \\
\hline 1. & Ya & 38 & 43,7 \\
\hline 2. & Tidak & 49 & 56,3 \\
\hline & Jumlah & $\mathbf{8 7}$ & $\mathbf{1 0 0}$ \\
\hline
\end{tabular}

Berdasarkan tabel di atas dapat diketahui bahwa dari 87 responden, yang mengalami kelainan letak janin sebanyak $38(43,7 \%)$ responden, sedangkan yang tidak mengalami kelainan letak janin sebanyak $49(56,3 \%)$ responden.

Tabel 3. Distribusi Frekuensi Responden Berdasarkan Preeklamsia

\begin{tabular}{cccc}
\hline $\begin{array}{c}\text { N } \\
\text { o }\end{array}$ & $\begin{array}{c}\text { Preeklamsi } \\
\mathbf{a}\end{array}$ & $\begin{array}{c}\text { Frekuensi } \\
(\mathbf{N})\end{array}$ & $\begin{array}{c}\text { Persentase } \\
(\boldsymbol{\%})\end{array}$ \\
\hline 1. & Ya & 34 & 39,1 \\
\hline 2. & Tidak & 53 & 60,9 \\
\hline & Jumlah & $\mathbf{8 7}$ & $\mathbf{1 0 0}$ \\
\hline
\end{tabular}

Berdasarkan tabel di atas dapat diketahui bahwa dari 87 responden, yang mengalami Preeklamsia berjumlah 34 $(39,1 \%)$ responden, sedangkan yang tidak mengalami preeklamsia berjumlah $53(60,9 \%)$ responden.

\section{Tabel 4. Distribusi Frekuensi Responden Berdasarkan Ketuban Pecah Dini}

Berdasarkan tabel di atas dapat diketahui bahwa dari 87 responden, yang mengalami ketuban pecah dini berjumlah $32(36,8 \%)$ responden, sedangkan responden yang tidak mengalami ketuban pecah dini sebanyak $55 \quad(63,2 \%)$ responden.

\begin{tabular}{|c|c|c|c|c|c|c|c|c|}
\hline \multirow{3}{*}{$\begin{array}{c}\text { Kelaina } \\
\text { n Letak } \\
\text { Janin }\end{array}$} & \multicolumn{4}{|c|}{ Sectio Caesarea } & \multirow{2}{*}{\multicolumn{2}{|c|}{ Jumlah }} & \multirow{3}{*}{$\begin{array}{c}p \\
v a l \\
u e\end{array}$} & \multirow{3}{*}{$\begin{array}{c}O R \\
95 \% \\
C I\end{array}$} \\
\hline & \multicolumn{2}{|c|}{ Ya } & \multicolumn{2}{|c|}{ Tidak } & & & & \\
\hline & $\mathbf{N}$ & $\%$ & $\mathbf{n}$ & $\%$ & $\mathrm{~N}$ & $\%$ & & \\
\hline Ya & 28 & $\begin{array}{c}73 \\
7\end{array}$ & 10 & $\begin{array}{c}26 \\
3\end{array}$ & 38 & $\begin{array}{c}10 \\
0\end{array}$ & $\begin{array}{l}0,0 \\
01\end{array}$ & 4,822 \\
\hline Tidak & 18 & $\begin{array}{c}36 \\
7\end{array}$ & 31 & $\begin{array}{c}63 \\
3\end{array}$ & 49 & $\begin{array}{c}10 \\
0\end{array}$ & $\begin{array}{l}\text { (Ber } \\
\text { mak }\end{array}$ & 12,181 \\
\hline Jumlah & 46 & & 41 & & 87 & & na) & \\
\hline
\end{tabular}

\section{Tabel 5. Hubungan Kelainan Letak Janin dengan Persalinan Sectio Caesarea}

Berdasarkan tabel di atas dapat diketahui bahwa dari 38 responden yang mengalami kelainan letak janin dan dilakukan persalinan sectio caesarea sebesar $28(73,7 \%)$ responden dan yang tidak ada kelainan letak janin dan tidak mengalami persalinan sectio caesarea berjumlah $10 \quad(26,3 \%)$ responden, sedangkan dari 49 responden yang tidak ada kelainan letak janin dan dilakukan sectio caesarea sebanyak $18 \quad(36,7 \%)$ responden dan yang tidak dilakukan sectio caesarea sebanyak 31(63,3\%) responden.

Berdasarkan hasil uji statistik Chisquare diperoleh nilai $p$ value sebesar $0,001(<\alpha=0,05)$ artinya ada hubungan yang bermakna antara kelainan letak janin dengan persalinan sectio caesarea di Rumah Sakit TK. IV Dr. Noesmir Baturaja Tahun 2018. Dengan demikian hipotesa yang menyatakan ada hubungan antara kelainan letak janin dengan persalinan sectio caesarea terbukti secara statistik.

Dari hasil analisis diperoleh pula nilai Odds Rasio $(O R)=4,822$ (1,90912,181)artinya ibu yang mengalami kelainan letak janin sungsang/lintang memiliki resiko 4,822 atau 5 kali 
mengalami persalinan sectio caesarea dibandingkan dengan responden yang tidak ada kelainan letak janin.

\section{Tabel 6. Hubungan Preeklamsia dengan Persalinan Sectio Caesarea}

\begin{tabular}{|c|c|c|c|c|c|c|c|c|}
\hline \multirow{3}{*}{$\begin{array}{c}\text { Preekl } \\
\text { amsia }\end{array}$} & \multicolumn{4}{|c|}{ Sectio Caesarea } & \multirow{2}{*}{\multicolumn{2}{|c|}{ Jumlah }} & \multirow{3}{*}{ p value } & \multirow{3}{*}{$\begin{array}{c}\text { OR } \\
95 \% \\
C I\end{array}$} \\
\hline & \multicolumn{2}{|c|}{ Ya } & \multicolumn{2}{|c|}{ Tidak } & & & & \\
\hline & $\mathbf{n}$ & $\%$ & $\mathbf{n}$ & $\%$ & $\mathbf{N}$ & $\%$ & & \\
\hline Ya & 24 & $\begin{array}{c}70, \\
6 \\
\end{array}$ & 10 & $\begin{array}{c}29, \\
4 \\
\end{array}$ & 34 & 100 & & $\begin{array}{c}3,38 \\
2\end{array}$ \\
\hline Tidak & 22 & $\begin{array}{c}41 \\
5\end{array}$ & 31 & $\begin{array}{c}58, \\
5\end{array}$ & 53 & 100 & $\begin{array}{c}\mathbf{0 , 0 1 5} \\
\text { (Berma } \\
\text { kna) }\end{array}$ & $\begin{array}{c}(1,35 \\
0- \\
8,46\end{array}$ \\
\hline $\begin{array}{c}\text { Jumla } \\
\mathbf{h}\end{array}$ & 46 & & 41 & & 87 & & & 9) \\
\hline
\end{tabular}

Berdasarkan tabel di atas dapat diketahui bahwa dari 34 responden yang mengalami preeklamsia dan dilakukan persalinan sectio caesarea sebesar 24 (70,6\%) responden dan yang tidak dilakukan sectio caesarea berjumlah 10 $(29,4 \%)$ responden,sedangkan dari 53 responden yang tidak mengalami preeklamsia dan dilakukan sectio caesarea sebanyak $22(41,5 \%)$ responden dan yang tidak dilakukan sectio caesarea berjumlah $31(58,5 \%)$ responden.

Berdasarkan hasil uji statistik Chisquare diperoleh pula nilai $p$ value sebesar $0,015(<\alpha=0,05)$ artinya ada hubungan yang bermakna antara preeklamsia dengan persalinan sectio caesarea di Rumah Sakit TK. IV Dr. Noesmir Baturaja Tahun 2018. Dengan demikian hipotesa yang menyatakan ada hubungan antara preeklamsia dengan persalinan sectio caesarea terbukti secara statistik.

Dari hasil analisis diperoleh pula nilai Odds Rasio(OR) sebesar 3,382 $(1,350-8,469)$ yang artinya responden yang mengalami preeklamsia memiliki risiko 3,382 atau 3 kali mengalami persalinan sectio caesarea dibandingkan dengan responden yang tidak mengalami preeklamsia.
Tabel 7. Hubungan Ketuban Pecah Dini dengan Persalinan Sectio Caesarea

\begin{tabular}{|c|c|c|c|c|c|c|c|c|}
\hline \multirow{3}{*}{$\begin{array}{c}\text { Ketub } \\
\text { an } \\
\text { Pecah } \\
\text { Dini }\end{array}$} & \multicolumn{4}{|c|}{ Sectio Caesarea } & & & \multirow{3}{*}{$\begin{array}{c}p \\
\text { valu } \\
e\end{array}$} & \multirow{3}{*}{$\begin{array}{c}\text { OR } \\
95 \% C I\end{array}$} \\
\hline & \multicolumn{2}{|c|}{ Ya } & \multicolumn{2}{|c|}{ Tidak } & \multicolumn{2}{|c|}{ Jumlah } & & \\
\hline & $\mathrm{n}$ & $\%$ & $\mathrm{n}$ & $\%$ & $\mathrm{~N}$ & $\%$ & & \\
\hline Ya & 26 & 81,3 & 6 & 18,8 & 32 & 100 & \multirow{3}{*}{$\begin{array}{c}\mathbf{0 , 0 0} \\
\mathbf{0} \\
(\text { Berm } \\
\text { akna) }\end{array}$} & \multirow{3}{*}{$\begin{array}{r}7,583 \\
(2,670- \\
21,540)\end{array}$} \\
\hline Tidak & 20 & 36,4 & 35 & 63,6 & 55 & 100 & & \\
\hline Jumlah & 46 & & 41 & & 87 & & & \\
\hline
\end{tabular}

Berdasarkan tabel di atas dapat diketahui bahwa dari 32 responden yang mengalami ketuban pecah dini dan dilakukan persalinan sectio caesarea sebesar $26(81,3 \%)$ responden dan yang tidak dilakukan berjumlah $6 \quad(36,4 \%)$ responden, sedangkan dari 55 responden yang tidak mengalami ketuban pecah dini dan dilakukan sectio caesarea berjumlah $20(36,4 \%)$ responden dan yang tidak dilakukan sectio caesarea berjumlah 35 $(63,6 \%)$ responden.

Berdasarkan hasil uji statistik Chisquare diperoleh nilai $p$ value sebesar $0,000(<\alpha=0,05)$ artinya ada hubungan yang bermakna antara ketuban pecah dini dengan persalinan sectio caesarea di Rumah Sakit TK. IV Dr. Noesmir Baturaja Tahun 2018. Dengan demikian hipotesa yang menyatakan ada hubungan antara ketuban pecah dini dengan persalinan sectio caesarea terbukti secara statistik.

Dari hasil analisis diperoleh pula nilai Odds rasio(OR) sebesar 7,583 (2,67021,540)yang artinya responden yang mengalami ketuban pecah dini memiliki risiko 7,583 atau 7 kali mengalami sectio caesarea dibandingkan dengan responden yang tidak mengalami ketuban pecah dini.

\section{KESIMPULAN}

Dari hasil penelitian di Rumah Sakit TK. IV Dr. Noesmir Baturaja Kabupaten Ogan Komering Ulu Tahun 2018 dapat disimpulkan bahwa:

1. Ada hubungan kelainan letak janin, preeklamsia dan ketuban pecah dini secara 
simultan dengan persalinan sectio caesarea di Rumah Sakit TK. IV Dr. Noesmir Baturaja tahun 2018.

2. Ada hubungan yang bermakna antara kelainan letak janin secara parsial didapatkan nila $p$ value 0,001 dengan persalinan sectio caesarea di Rumah sakit TK IV Dr. Noesmir Baturaja tahun 2018.

3. Ada hubungan yang bermakna antara preeklamsia secara parsial didapatkan nilai $p$ value 0,015 dengan persalinan sectio caesarea di Rumah sakit TK IV Dr. Noesmir Baturaja tahun 2018.

4. Ada hubungan yang bermakna antara ketuban pecah dini secara parsial didapatkan nilai $p$ value 0,000 dengan persalinan sectio caesarea di Rumah sakit TK IV Dr. Noesmir Baturaja tahun 2018.

\section{SARAN}

Berdasarkan hasil pembahasan pada penelitian ini, maka peneliti menyarankan :

\section{Kepada Rumah Sakit TK. IV Dr. Noesmir Baturaja}

Hasil penelitian diharapkan dapat memberikan masukan kepada para pimpinan rumah sakit dalam membuat kebijakan dan dapat menambah pengetahuan mengenai hubungan kelainan letak janin, preeklamsia, dan ketuban pecah dini dengan persalinan sectio caesarea di Rumah sakit TK IV Dr. Noesmir Baturaja Tahun 2018.

\section{Kepada Universitas Kader Bangsa Palembang}

Hasil penelitian ini diharapkan dapat digunakan sebagai referensi atau kajian baik di tingkat fakultas maupun universitas, serta menambah dan memperkaya hasil-hasil penelitian, khususnya yang berkaitan dengan persalinan sectio caesarea.

\section{Kepada Peneliti yang akan dating}

Hasil penelitian ini diharapkan dapat menjadi bahan pertimbangan atau perbandingan bagi peneliti lain yang akan melakukan penelitian sejenis pada masa yang akan datang.

\section{UCAPAN TERIMA KASIH}

1. Suami dan Kedua Orang tua(Suami Dwi Vino Zera,Ayah H.Syamsul Kamil dan Ibu $\mathrm{Hj}$. Masnarila), yang selalu memberikan dukungan, semangat, dan do'a yang tiada hentinya.

2. Anak-anakku (Elvina Syaqila Mumtazah dan Aiza Nuha Mafaza), terima kasih telah menjadi anak-anak terbaik untuk mama.

3. Dosen pembimbing Materi ibu $\mathrm{Hj}$. Herawati, M.Kes dan dosen pembimbing Teknis Ibu Hj. Sutriyati, M.Kes ucapan terima kasih yang tak terhingga untuk waktu, ilmu, nasihat dan kesabarannya dalam memberikan bimbingan kepadaku selama ini.

4. Dosen dan Staf Universitas Kader Bangsa Palembang prodi Diploma IV Kebidanan, terima kasih untuk semua do'a dan bimbingannya.

5. Staf RS TK IV DR.Noesmir Baturaja yang telah membantuku dalam melakukan penelitian di RS TK IV DR.Noesmir Baturaja

6. Terimakasih juga ku persembahkan kepada keluarga dan sahabatsahabatku yang senantiasa menjadi penyemangat ku

7. Teman-teman satu angkatan perjuanganku yang selalu membantu, berbagi keceriaan dan melewati setiap suka dan duka selama kuliah, terima kasih banyak

\section{DAFTAR PUSTAKA}

Aprina.2015. Faktor-faktor yang

berhubungan dengan Persalinan Sectio

Caesarea Jurnal Kesehatan, Volume VII,

Nomor 1, April, 2016 ,hlm 90-96 
Dinkes Sumsel, 2017. Profil kesehatan

Sumatera Selatan

Notoatmodjo, 2010. Metodelogi penelitian kesehatan. Rineka Cipta :Jakarta 2012. Metodelogi penelitian kesehatan. Rineka Cipta:Jakarta Mamede. 2012 .Kebidanan Patologi. Nuha Medika: Yogyakarta

Mochtar, Rustam. 2012.Sinopsis Obstetri. EGC:Jakarta

Oxorn, H. \& Forte, WR .2010. Ilmu Kebidanan : Patologi dan Fisiologi Persalinan, Yayasan Essentia Medica (YEM) : Yogyakarta

Winkjosastro, Hanifa.2012. Ilmu Bedah Kebidanan. Yayasan Bina Pustaka:Jakarta 